Japan. J. Med. Sci. Biol., 19, 253-258, 1966

\title{
A HISTOPATHOLOGIC STUDY OF LYMNEA AURICULARIA VAR RUFESCENS INFECTED WITH THE LARVAL STAGES OF ECHINOSTOMA REVOLUTUM
}

\author{
M. M. PATNAIK AND S. K. RAY \\ State Veterinary Laboratory, Bhubaneswar-3, India
}

(Received: August 26th, 1966)

\begin{abstract}
The histopathology of Lymnea auricularia var rufescens parasitized by the larval stages of Echinostoma revolutum was studied. The location of different stages and their induced effects on various organs including the noticeable changes around encysted metacercariae are described. The path of invasion was found to be through lymphatics. Development of the precercarial stages in the muscles of foot and mantle wall was observed.
\end{abstract}

\section{INTRODUCTION}

In an earlier paper, the life history of Echinostoma revolutum (Froleich, 1802) involving the snail, Lymnea auricularia var rufescens Gray 1822, as primary and secondary intermediate host and brief morphological and behavioural changes in the infected snail host was described (Patnaik and Ray, 1966). The specific histopathological changes produced by the larval stages of $E$. revolutum, their location in this snail host and those features distinct from the classical work of Hurst (1927) on the structural and functional changes produced by the larval stages of this trematode in Physa occidentalis are presented in this paper.

\section{MATERIALS AND METHODS}

Examination of 703 snail specimens of $L$. auricularia var rufescens for natural infection of $E$. revolutum during 1965-66, revealed the infection in 97 snails. Of them, 13 deshelled entire specimens were fixed in $70 \%$ alcohol and $5 \%$ formaline mixture $(10: 1)$ or Bouin's fluid, embedded in paraffin, serially sectioned at 7-10 microns thick and stained with Ehrlich's hematoxylin and eosin. Van Gieson's picrofuchsin as counter stain for detecting connective tissue, thionin blue for mucin and cystogenous glands in selected cases were employed. Similarly treated uninfected snails were utilized for comparison.

\section{RESULTS}

All snails harbored the developmental stages of E. revolutum only. Most parts of the snail body except for the denser muscular parts, were found infected by the parasitic stages. Owing to shrinkage of host tissue and parasitic stages during fixation, varying

This investigation was supported in part by a grant from the Board of Scientific and Industrial Research, Orissa to Shri. M. M. Patnaik. 
degrees of "halo" were found around each stage. The sacular sporocysts filled with germ balls, imgratory developing redia were commonly seen inside the lymph spaces, connective tissue spaces, and inter-glandular locations. The first and second generation radiae and the liberated cercariae were usually found in the inter-acinar spaces of hepatopancreas. Encysted forms of metacercaria were found mainly in the superficial regions of the muscular foot; connective tissue matrix and other denser locations. The redial stages appeared most invasive and pathogenic and were always found in the lymph spaces during their early stage. Traumatic injuries during liberation of cercariae were observed in all parts of the snail except deeper parts of muscular foot. Besides the above usual sites, several unusual locations were also occupied by the larval stages, wherein they developed.

The relative pathogenic effects produced by the larval stages in different locations of the snail hosts was of the following order.

Hepatopancreas: This organ was invariably found infected with most of the larval stages. The entire gland was enlarged. The damages brought about by the first and second generation redia and their liberated cercaria were profound. Besides the mechanical changes of displacement of glandular structures, resulting from pressure exerted by the growing parasites on the adjoining tissue, rediae gnawing and devouring cellular elements, the degenerative or atrophic changes in unaffected glands, histolytic changes particularly around the second generation redia shedding cercariae, were commonly observed. The glandular epithelium and underlying tissue stroma were mechanically damaged by the shifting redia. In the heavily infected snails, the hepatic acinar tissue was limited to the tunica propria. Decrease in volume of glandular substance was noticed. The parasitic forms occupied the central part. In some the continuity of the tunica propria was broken in many places and sloughing in part was observed.

The degenerative cellular changes included-irregular vacuole formation in the distal end of the glandular epithelium, "fatphanerosis" as seen from small circular vacuoles left by dissolved fat, decrease in globular contents of the cuboidal calcium basal cells and increase in granular contents of hepatic cells, shifting of the basal nuclei of the columnar cells towards the middle third (distally) and loss of distinct cell boundary. The necrobiotic changes in the nuclei - were pyknosis, karyorrhexis and spreading of karyorohetic materials in the cell whose definite structure was lost, karyolysis and necrosis. Syncytial nucleated mass in basal parts of cells were occassionally seen in the distally located acini, undergoing pressure atrophic changes. In the vicinity of the parasitic stages acellular exudative changes in the unaffected glandular acini was marked. (Fig. 1) Oedematous changes in the gland was common.

Kidney: In the affected kidney the excretory space in between the tubular folds was enormously increased. The lymphatic spaces in between the two basal layers of renal tubules were invaded by the migratory stages of redia and other subsequent developmental stages. Such affected parts were distended (Fig. 2).

The attendant cellular changes in the single-celled renal epithelium which had uniform distal excretory vacuoles, were relatively larger sized and contained granular substances around the nuclei in the basal part and eosino-spherical globules in the vacuoles. The margins of such cells were not clear-cut. The degenerating cells had larger concretions and the basal spherical nuclei had taken oval shape. Karyorrhexis in the adjescent cells and amebocytes in lymphatics particularly around the parasite was seen. Heavy infection in this organ was not marked.

Connective tissue: The connective tissue matrix, in-between the visceral parts, con- 
tained ail stages. Profound oedematous changes around the migratory stages and histolytic changes around the precercarial stages were common. Around the encysted forms of metacercaria, except for encapsulation the changes were less significant (Fig. 3).

Gonads: In heavily infested snails the ovotestis and other accessory glands were attacked by the developing rediae. Disrruption and histolytic changes in the gland was marked. In some cases the gonads were reduced in size, on account of pressure exerted by the mass of growing parasites in this or adjescent locations and were limited to a part. Characteristic basophilic staining affinity was less intense and appeared less functionary. Complete disappearance was not observed. Encysted forms in the interglandular connective tissue were often seen.

Alimentary system: Infection in the anterior part of the gut up to stomach was not marked. In the intestine the submucosal parts of the gut wall was infested by the rediae, liberated cercariae and the encysted forms of metacercaria. Apparently, they invaded from the peripheral parts and remained embeded, underneath the tunica.

No significant change in the secretory mucosal layer was observed, except for distension or protrusion of the part, into the lumen. Infestation with large numbers of such stages may result in decreased function (motility) of the gut and mechanical obstruction in lumen.

Other locations: The muscular part of the mantle wall was often seen to be infected with all stages. Mechanical distension due to growing parasitic stages, oedema of the part, and degeneration of the under-surface epithelium was observed. Black pigments lining the cell boundary was the common feature. Development in the embeded precercarial stages was marked. Mostly encysted forms were encountered.

In the denser muscular tissue, occassionally the migratory rediae were seen. Development to the second generation redia and cercariae was noticed. Encapsulation of such stages, as with metacercariae, was not observed. (Fig. 4).

Muscular foot: Penetration of cercaria into the superficial soft muscular parts through the surface columnar epithelial layer into the subepithelial region was not observed, but trails of disoluted tissue fleading to recently encysted forms, whose reactionary second layer of cyst wall had not completely been formed by the host was marked. Individual encystment in the subepithelial glandular parts, was invariably found and often in large numbers in a single location. Each cyst was encapsulated by reactionary connective tissue stroma. In all sections this connective tissue layer was separated out from the yellowish hyaline cyst wall elaborated by the metacercariae leaving a clear " halo". The metacercariae were further shrunken and lay flexed inside the cyst and contained no cystogenous gland (Fig. 5). Each metacercaria measured 65.5-91.74 $\times 50.04-55.5$ microns including their cyst and their "halo" measured $96-116 \times 66.72-100$ microns. The tentacles were not infested. They were seldom seen in deep denser muscular parts and in the denser basophilic pedal glands, but always found in fofter vacuolated parts in the subepithelium amidist slime glands. (Fig. 6).

The infected muscular parts were oedematous, flabby and appeared less contractile. The secretary slime glands in the affected region were scarce and the surface epithelium was limited to a mere line. Erosion and sloughing of heavily infested parts leaving ulcers was seen in some. Dark pigments (Black) were seen in the glandular region of the foot. The amobocytes in the denser parts were rare but around the affected parts they were often present. 


\section{DISCUSSION}

From the precise location of the migratory stages it was believed that the path of infection in this snail was through lymphatics.

Contrary to the findings of Hurst (1927) encystment in the hepatopancreas was seldom seen, but karryolytic changes of the hepatopancreatic nuclei, little change in karrosomes of renal cells of the infected kidney, oedematous changes due to intrusion of cercariae for encystment in foot, were observed. Complete absence of gonads, shrunken appearance of foot, encystment in all parts of the body including outer surface of the shell, as reported by him, were not encountered. Total replacement with cells, simillar to stratified epithelium or to a syncitial nucleated mass and loss of calcium globules, as reported by Lal and Premvati (1955) in hepatopancreas was not observed. The presence of a large gut in the voracious redia, causes dammages simillar to those reported by Abdel-Malek (1958) in case of the echinostome, Petasiger chandleri, which caused reduction of $78 \%$ of hepatic tubules and $95 \%$ of ovotestis acini in Helisoma corpulentum Say. The present findings, however, embrass all the major pathological changes in hepatopancreas and gonads, as summarised by Cheng and Snyder (1962), in their comprehensive review on the hostparasite relationships. Encapsulation of the developing migratory forms in foot as reported by Cheng and Cooperman (1964) was not found and development in them was noticed.

Hurst (loc. cit.) considered encystment of metacercariae in the muscular foot was not pathogenic. In the present study it is seen initial disolution of host tissue around the intruding cercariae for encystment and proliferation of the connective tissus lying in close proximity, to form the second reactionary layer, in common with the findings of Lal and Baugh (1955). Such encystment in large numbers in the muscular foot initially caused oedema and reduced slime secretions, sloughing in parts and other cellular changes indicate that they are pathogenic to the snail host.

The organic dammages caused by the precercarial stage were responsible for their reduced rate of growth and spawning and the pathological changes caused by the encysting metacercariae were responsible for their lethargic behaviour, as reported earlier by Patnaik and Ray (loc. cit.).

Brief excursion of carcariae out of the snail host before encystment, even in the same snail, appeared essential on the part of trematode as migration through the denser muscular parts to superficial subepithelial locations seemed difficult and unusual, in contrary to the remarks of Daws (1956) that this excursion in not through the general prccedure but taken some times.

The authors wish to express their gratitude to Dr. Y. Komiya, Chief of Department of Parasitology, National Institute of Health, Tokyo, for his helpful criticism in final preparation of this paper and to Dr. H. S. Bawa, Director of Animal Husbandry and Veterinary Services, Orissa, for the facilities.

\section{REFERENCES}

ABDEL-MALEK, E. (1958): Factors conditioning the habitat of bilharziasis intermediate hosts of the family planorbidae. Bull. Wld. Hlth. Org., 18, 785-818.

Cheng, T. C. AND Coopeman, J. S. (1964): Studies on host-parasite relationships between larval trematodes and their hosts. V. The invasion of the reproductive system of Helisoma triyolvis by the sporocysts and cercaria of Glypthelmins pensylvaniensis. Trans. Am. Micro. 
Soc., 83, 12-23.

Cheng, T. C. AND SNyder, R. W. (1962): Studies on the host parasite relationship between larval trematodes and their host. I. A Review. II. The utilisation of the host's glycogen by the intramolluscan larva of Glypthelmins penusylvaniensis Cheng and associated phenomenon. Trans. Am. Microsp. Soc., 81, 209-228.

DAws, B. (1964): The trematoda., Cambridge Univ. Press., 644. pp.

Hurst, C. T. (1927): Structural and functional changes produced in the gastropod mollusc. Physa occidentalis, in the case of parasitism by the larval of Echinostoma revolutum. Univ. Cal. Publ. Zool., 29, 321-404.

LAL, M. B. AND BAUgh, S. C. (1955): Studies in histopathology-effects of the presence of a plagiorchid metacercaria on the tissues of the snail Vivipara bengalensis (Lamark), Proc. Indian. Acad. Sci. Section B, 42, 114-122.

LAL, M. B. AND PREmivati (1955): Studies in histopathology changes induced by larval monostome in the digestive gland of the snail, Melanoides tuberculatus (Muller). Proc. Indian. Acad. Sci., Section B, 42, 193-299.

PATnAIK, M. M. AND RAY, S. K. (1966) : On the life history and distribution of Echinostoma revolutum (Froleich, 1802) in Orissa. Indian. Vet. J., 43, 591-600.

\section{EXPLANATION OF FIGURES}

Fig. 1: Photomicrograph showing cross-section of the hepatopancreas of a heavily infected snail. Note the redia containing developing larval stages in the interglandular lymphatic space. Exudative and degenerative changes in the lumen of the gland. $(\times 70)$

Fig. 2: Photomicrograph showing the section of kidney tubules containing the migratory stages of redia in the lymphatic spaces. Note the distending changes in the excretory cells lining the kidney tubules. $(\times 170)$.

Fig. 3: Photomicrograph showing the section passing through the interglandular connective tissue having different developing larval stages. Note the reactionary proliferative changes around the metacercaria, mechanical destructive changes around the redia shedding cercaria and smoothened boundary around developing redia. $(\times 60)$

Fig. 4: Photomicrograph showing the cross section of mature second generation redia containing various developmental stages including cercaria and a migratory first generation redia above in the denser muscular foot. $(\times 170)$

Fig. 5: Photomicrograph showing the cross section through a portion of muscular foot. Note numerous encysted forms of metacercaria in the subepithelial parts along the periphery and the reactionary lining around the cyst. $(\times 160)$

Fig. 6: Photomicrograph showing the cross section through a portion of muscular foot Note numerous encysted forms of metacercaria in the loose vacuolated subepithelial parts and disolution of surface epithelium along the periphery but the denser glandular and muscular parts remained unaffected. $(\times 50)$ 


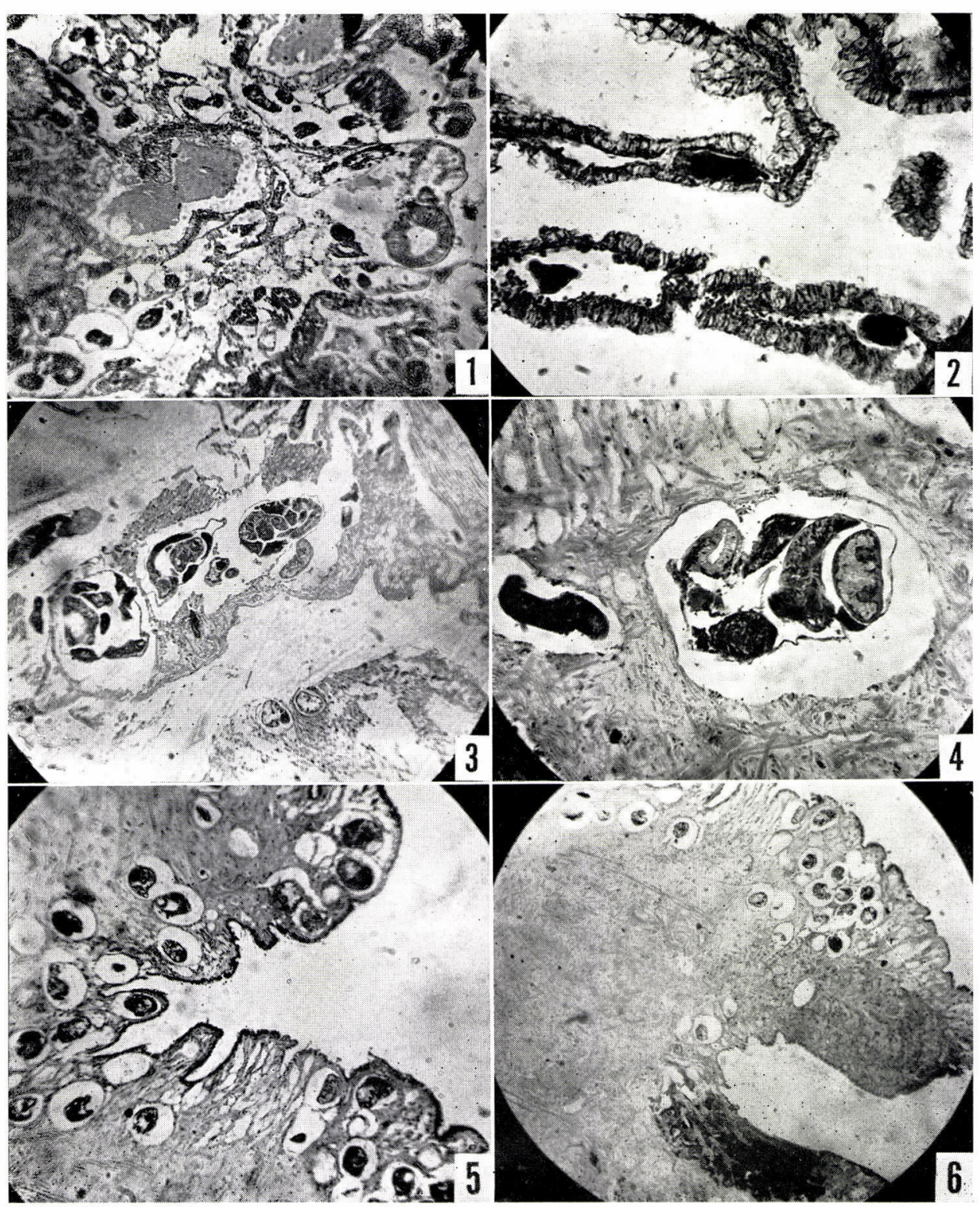

